\title{
Similar Tectonic Patterns on Earth and Moon
}

\author{
P. Hédervári (*) \\ Ricevuto il 16 Gennaio 1968
}

Summary. - Using a method, which is customary in comparative planeto - and geophysics, the author of the present paper stated the fact, that - in spite of certain differences - there is a very interesting and tectonically basically important similarity between the fault-system of the Red Sea - African Trenches region and the great Alpine Valley area of the Hoon. Shortly some other similar tectonic features are also mentioned.

The morphology of the Red Sea and of Alpine Valley are compared and on this basis similar tectonic processes are suggested for the interpreta. tion of their origin.

At the end of the article the author discusses the aim of planetology and the method of comparative planeto - and geophysics.

Riassunto. - Usando un metodo che è abituale nel confronto planetologico-geofisico l'A. stabilisce il fatto che - salvo alcune differenze è di grande interesse l'esistenza di una accentuata rassomiglianza tettonica fra il sistema fagliato del Mar Rosso-Fossa dei Grandi Laghi Africani e la Valle Alpina della Luna. Sono inoltre brevemente ricordate altre strutture tettoniche con analoghe caratteristiche.

Viene fatto un confronto fra la morfologia del Mar Rosso e quella della Valle Alpina, e su questa base, vengono suggeriti processi tettonici simili per l'interpretazione della loro origine.

Alla fine della nota, l'A. discute lo scopo della planetologia ell il metorlo di confronto planetologico-geofisico.

\section{Introduction. - Earlier Statements Congerning the Alpine VILLEY OF THE MOON.}

It has been well-known since long that the Sowiet spacecrafts of the "Luna "-series, the rocket " Zond", furthermore the American

(*) F.R.A.S., F.I.L.S., Vice-President of International Lunar Society. 
artificial celestial bodies ("Surveyors", " Rangers " and "Lunar Orbiters") made many excellent photos about the Moon's surface. Some of these photos had been published in different periodicals, such as "Sky and Telescope" and "Journal of International Lunar Society".

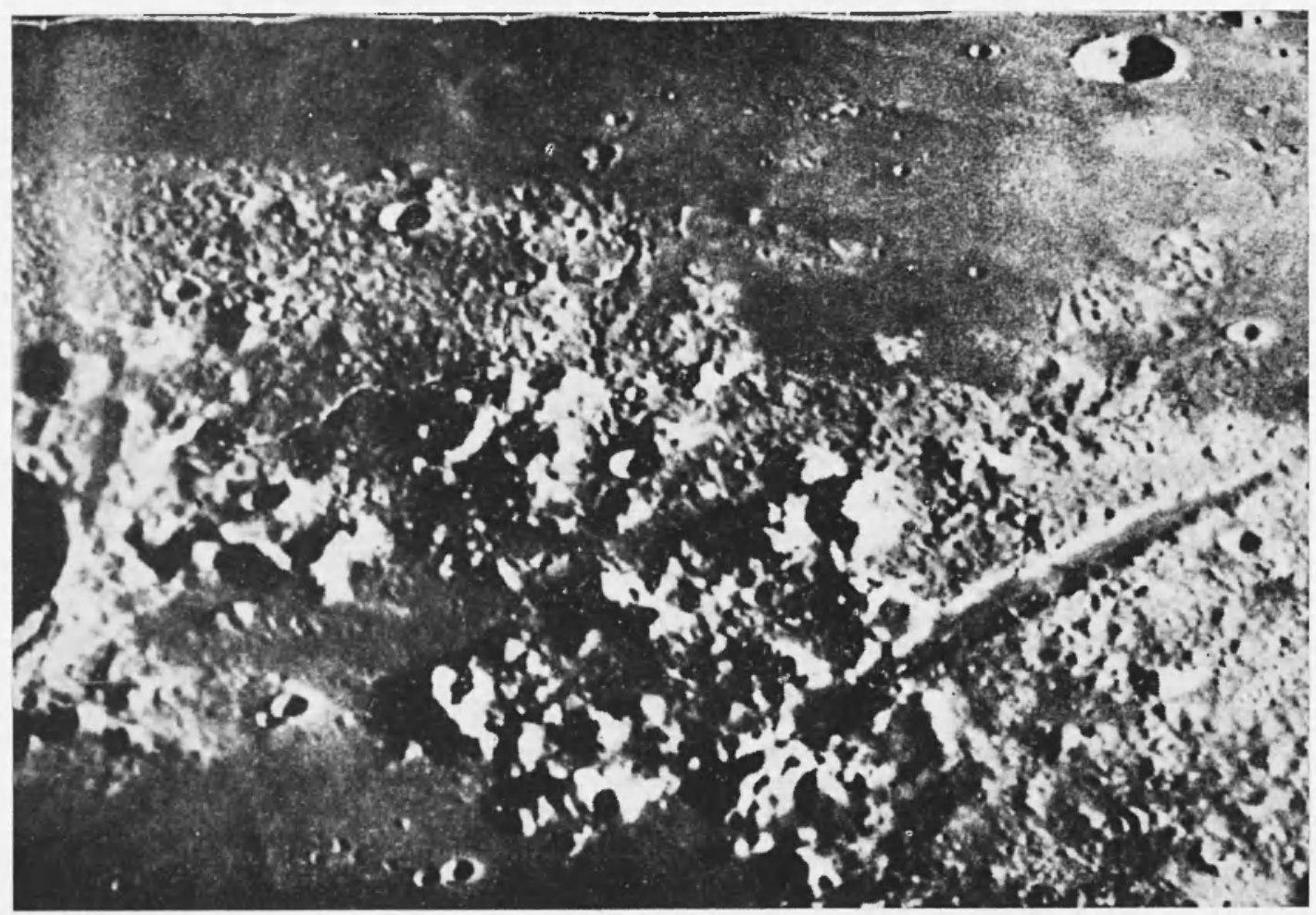

Photo I - The great Alpine Valley of the Moon. Photo was made by the 43 -inch reflector of Pic dn Midi Observatory (France), on $30^{\text {th }}$, Narch, 1966, (after Sky and Telescope).

Among these photos there are a very interesting one, appeared also in "Sky and Telescope" (1). This picture (Photo I) shows the region of the remarkable Alpine Valley of the Moon..

The earlier photos of the respective region of the lunar surface showed the Alpine Valley from an oblique view with a rather great perpectivical distortion. Even the most excellent pictures, made by the lagerst telescopes of the world, revealed only the rough outlines of the valley without the fine details. But the new 
photo, due to Lunar Orbiter 4 (Photo II), shows the valley without such a great distortion. Accordingly now we can see the true form of the area under consideration. Simultaneously, the Lunar Orbiter 4 photo has revealed some fine details, too, first of all the important rift (rille)

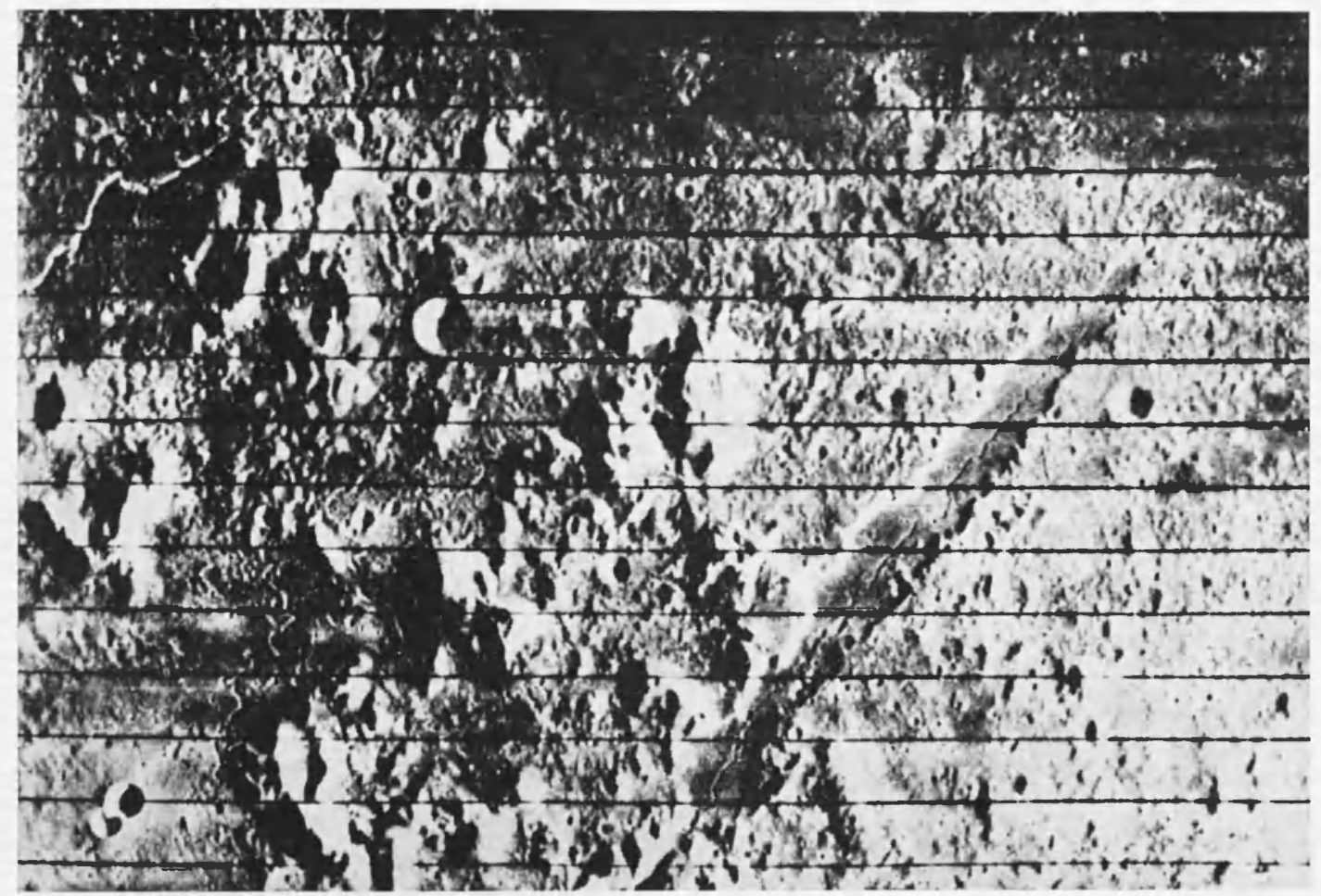

Photo II - The great Alpine Valley. The photo was made by Lunar Orbiter 4, about 1800 miles above the lunar surface, on 19th, May, 1967, (after Sky and Telescope).

which extends along the longitudinal axis of the valley. It can also be seen that in the proximity of the Alpine Valley there is a system of rilles (Figs. 1 and 2). The members of this system are zigzagged.

Regarding the morphology, dimensions and origin of the Alpine Valley, we can quote some illustrious lunar explorers, (in alphabetical order).

BALDWIN $\left({ }^{2}\right)$ wrote as follows: "It is an essentially perfect cut through the Alps, starting as a fine feature, widening to the middle 


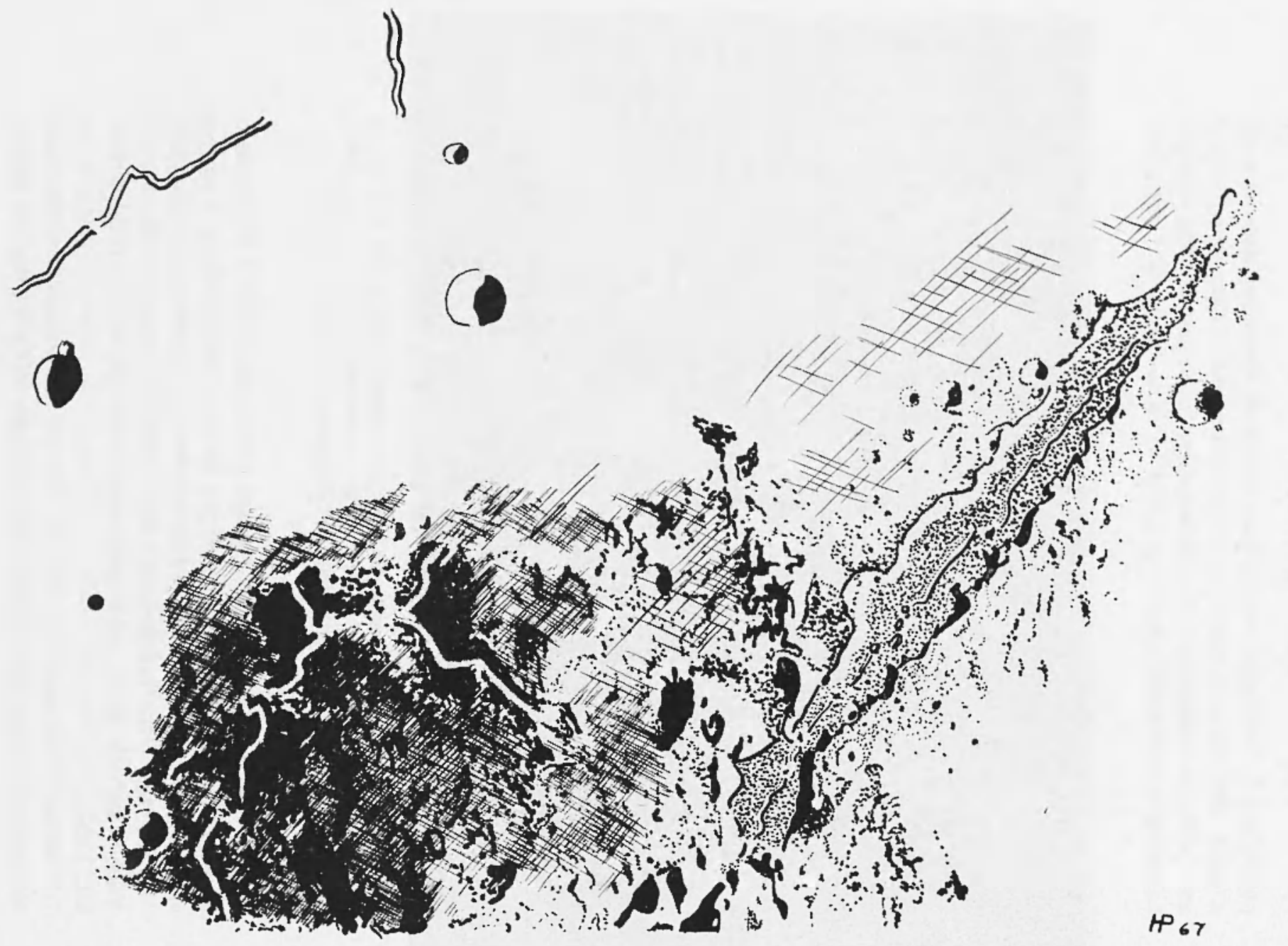

Fig. 1 - The great Alpine Valley. The drawing was made on the basis of Lunar Orbiter 4-photo (see Photo. II). Note the rilles inside the valley and its proximity, respectively. 


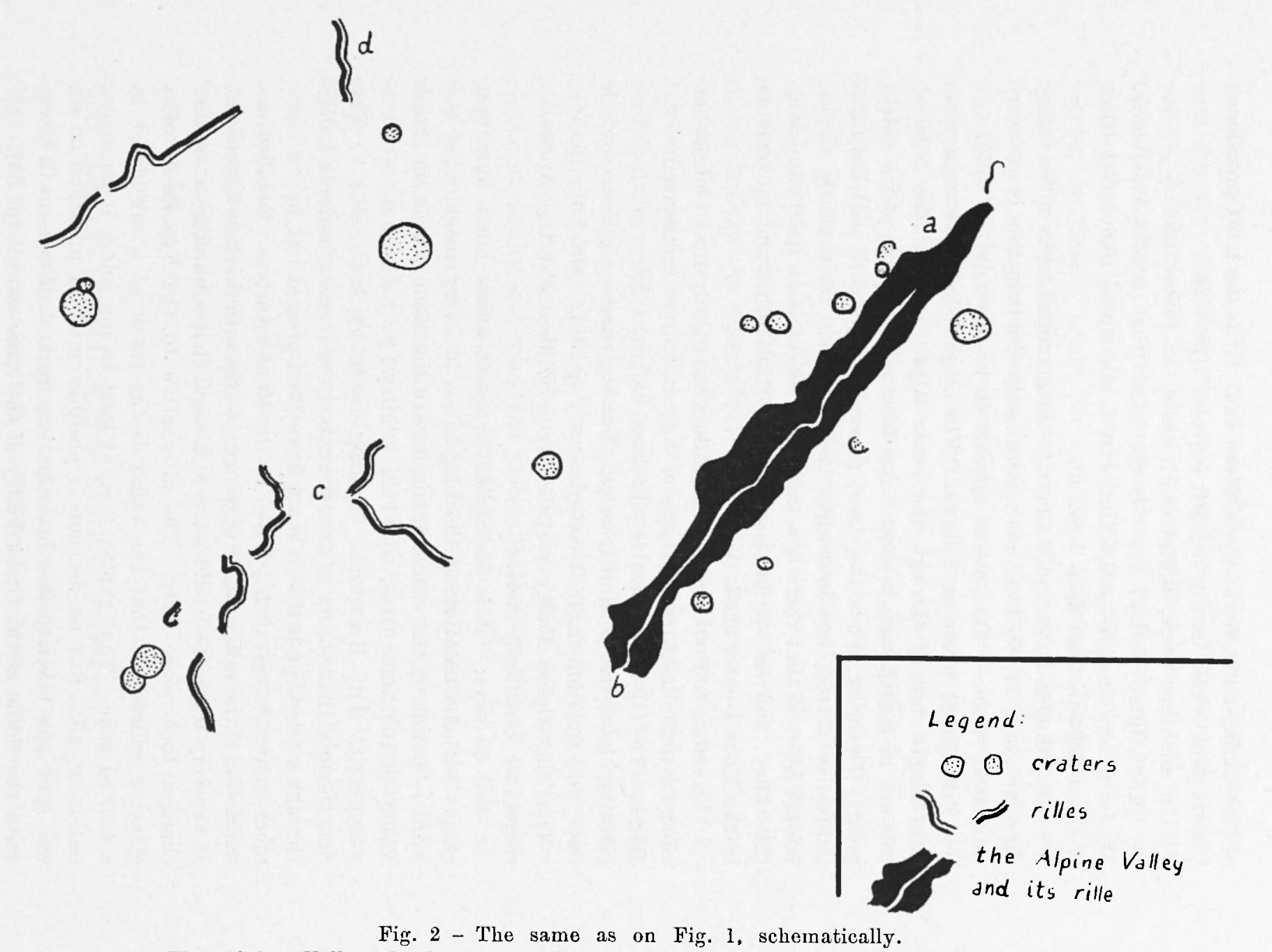


and becoming narrower at the western end. It is the most prominent feature of a whole family of such objects" (p. 322).

In an other work, B.ILDwIx $\left({ }^{3}\right)$ wrote the followings:

(The Alpine Valley) ... " is 83 miles (that is $133 \mathrm{kms}$ ) long, $3 \frac{1 / 2}{6} 6$ miles) (that is $5,6-9,6 \mathrm{kms}$ ) broad, and up to 10,000 feet (that is about 3000 metres) deep" (p. 42).

Arecording to Berr and M IDIfR (') the maximal depth of the valley may be about 11,000 feet, but according to Baldwin this is an overestimated value. "Its bottom appears to be flooded" (p. 207).

Fifider $\left({ }^{5}\right)$ wrote as follows: "The Alpine Valley forms a vast, cigar-shaped breach through the lunar Alps. It is of the order of $150 \mathrm{~km}$ in length, and is some $8 \mathrm{~km}$ from edge to edge at its widest point. Towering above the dark, generally apparently flat floor are impressive scarps, but in reality they probable have gentle slopes. Kuiper believes that there is a transverse fault about half way along the valley, and he attributes the valley itself to ground movements in the Moon's outer shells" (p. 161).

According to FrisowF ( $\left.{ }^{6}\right)$ : "the valleys are mainly due to subsidence along tectonic fractures, a type of formation not unknown on the Earth. The 70-mile (that is $112 \mathrm{kms}$ ) Mlpine Valley must almost certainly have had a similar origin, but its regular outline, smooth floor, and isolation make it conspicuous" (p. 38). And later (p. 41): "Thus the Alpine Valley is probably a graben and the Apennine ridges are essentially horsts".

LAY (") says: "it is impossible to speak about lunar mountain chains without mentioning the biggest - in every meaning of this word - puzzle on the visible hemisphere of the Moon. It is the Great Valley of the lunar Alps, which simply has no coun terpart on Earth. (Spacing made by me, P.H.) - The first thought that occurs to almost anybody who sees the Great Valley through a telescope is that it must have been gouged out by an enormous meteorite traveling parallel to the Moon's surface. Detailed examination of the valley fails to agree completely with this first impressant at the very least one would have to assume that a number of smaller changes took place later. The alternative to the hypothesis of a glancing collision is that the valley is the result of a subsidence in a faulted zone. That explanation, at least to my mind, is no explanation at all. But no decision is possible until an intestigation on the spot has taken place; investigation from a distance will never solve the riddle of the Great Valley of the lunar Alps" (p. 54). 
Moore ( $\left.{ }^{8}\right)$ wrote: "Associated with the Mare Imbrium (and also with the Mare Humorum) are vast numbers of wrinkle-ridges, crater valleys, graben and other faults which comprise a local grid system subradial to the mare. This tectonic pattern must certainly have been produced at the time of the formation of the mare, and theories involving an impact origin for the Mare Imbrium (Baldwin, 1963; Urey, 1957) seem to be completely out of court. Moore has shown that the cross-faults as.sociated with the Alpine Valley rule out any idea that the valley can have been due to a grazing meteorite, and the same argument can be applied to the numerous other components of the grid system" (p. 102). And later (p. 134-135): "The spectacular Alpine Valley, cutting right through the Alps, has a length of some 80 miles (that is $128 \mathrm{kms}$ ). '...' it is flanked by lofty elevations, and on its floor are some fine details, including two delicate clefts (Wilkins, 1955). ' ...' the suggestion by Gilbert (1893), supported by Urey and others, that it may have been produced by a missile slicing through the mountains is completely out of court for obvious reasons. It is too large and too deep; the bordering heights rise to 10,000 feet above the floor, and it is 6 miles wide at its broadest point. (Filder 1963) writes that ' all these characteristics, and the sinuosity and lobate enlargement of the valley at the Imbrian end, definitely refute the hypothesis that it was produced in one sweep by a projectile ejected from the Mare Imbrium'. Moreover, there is a very delicate system of parallel and transverse valleys, extremely difficult to photograph and visible only when suitable illuminated. '...' The floor of the valley is dark. '...' Fielder has drawn attention to the sinistral displacement that the fault makes on the two prominent blocks at its eastern end; the northern block has been moved, relatively, some 13 miles (that is about $21 \mathrm{kms}$ ) to the west. ' ...' It is a part of the deformation that occurred in connection with the Imbrian formation; in fact, it is part of the system of faults and throughs cutting the Apennines and $\mathrm{Alps}$ to form two, if not three, intersecting grids".

Last, but not least, we may quote Tounsas $\left({ }^{9}\right)$, according to him: (concerning the Alpine Valley): "is it possible that we have there a case of faulting?"

\section{Some Remarks Concerning the Earlers Statements.}

We can see that there are two kinds of opinion regarding the origin and the true nature of Alpine Valley of the Moon. Some authors 
had suggested that it is the consequence of the impact of a great meteorite or a planetoid which collided with the Moon and hit into the territory of the present Mare Imbrium. Accordingly the Alpine Valley orisinated by the effect either of a gigantic "splinter" of the respective planetoid or by a fragment of the solid lunar crust itself, which flew parallel with the surface and ploughed it up.

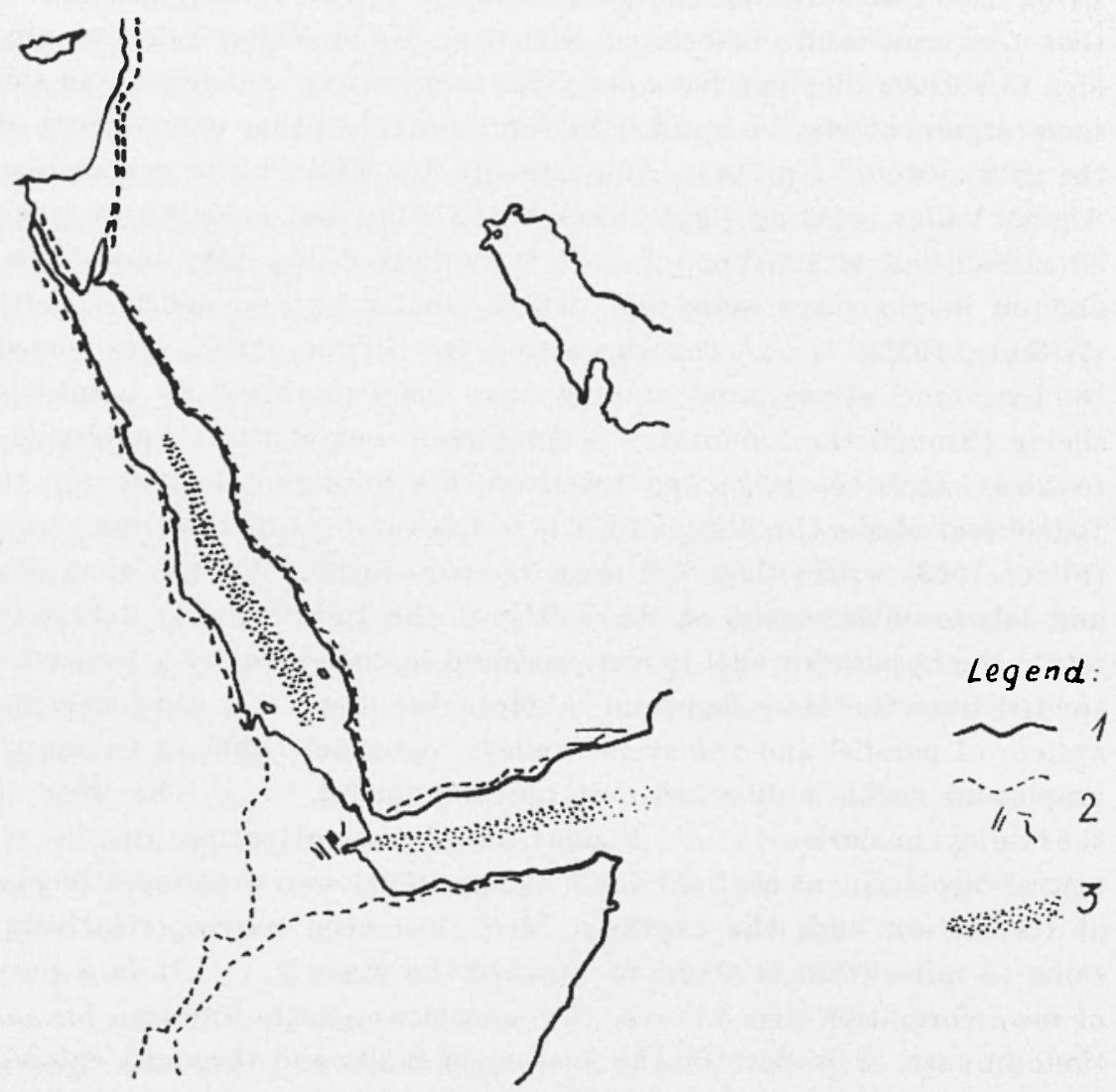

Fig. 3 - Map of the Red Sea.

Legend. 1: sea-shore; 2: faults; 3: fracture zones (after Girdler).

On the other hand, some other selenologists believe that the Alpine Valley may be a graben, that is a tectonical feature which was originated by internal forces, once had been active inside the Moon. HénFrVÁrI (10. ${ }^{11}$ ) has suggested that the Alpine Valley might have been the consequence of the general expansion of the Moon. This 
earlier hypothesis of the present author will be proved now by a morphological consideration, in the light of the new photo, made by artificial satellite Lunar Orbiter 4 . It must be emphasized that according to the new photo, mentioned above, there is a rift along the longitudinal axis of the valley, but this rift is zigzagge.l and not straight. It is clear, therefore, that the existence of this rift is explainable only by internal forces and in no case by the supposition of a great impact into the Mare Imbrium. The trace of a gigantic splinter, originated either from the planetoid or from the solid lunar crust, would have been straight and not zigzagged. This argument is of capital importance against the impact-origin of Alpine Valley.

Concerning the true dimensions of the valley there are certain differences among the mentioned author's data. Shortly, the length is

$$
\begin{aligned}
& 133 \mathrm{kms} \text { (Baldwin); } \\
& 150 \mathrm{kms} \text { (Fielder); } \\
& 112 \mathrm{kms} \text { (Firsoff); } \\
& 128 \mathrm{kms} \text { (Moore). }
\end{aligned}
$$

The mean value is $130,75 \mathrm{kms}$.

The present author is not on the opinion of Ley, according to him the lunar Alpine Valley has no counterpart on Earth. On the contrary, as we shall point out in the next chapters, the Alpine Valley is surprisingly similar, both morphologically and tectonically to one of the important basins of the Earth' surface!

\section{Morphological Comparison Between Rei Sea - African Trenches Region of the ElRTh iND the Alpine Valley Fault-ststem OF THE MOON.}

It is very conspicuous that the true from (that is the appearance) of the Alpine Valley resembles to the form of the Red Sea, from the Bab-el-Mandeb Strait as far as the Southern end of Sinai-peninsula. Evidently this similarity is not accidental at all. The morphological resemblance of these two features suggests similar origin and development.

Let us now see some details!

According to GIRDI,ER $(12,13,14,15)$ along the longitudinal axis of the Red Sea there is a narrow but long fracture-zone which extends from about the latitude of $24^{\circ} \mathrm{N}$ to about the latitude of $15^{\circ} \mathrm{N}$. 
Probably there may be a continuation of this fracture-zone toward the South, trough on the Bab-el-Mandeb Strait, and thus this zone is in a direct connection with the similar zone of fractures in the Gulf of Aden. However, on the other direction, that is toward the North, the zone of fractures doesn't reach the Northern end of the Red Sea (Fig. 3). In accordance with Girdler's wiew the respective two zones in the Red Sea and in the Gulf of Aden, respectively, represent regions of quasi-oceanic crust.

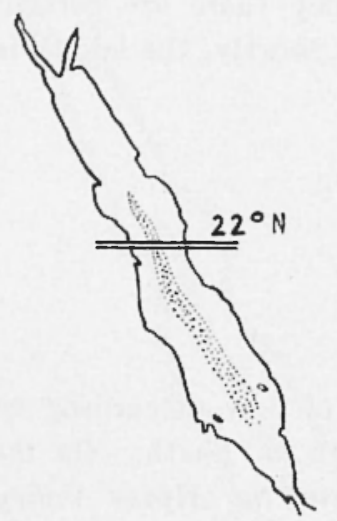

$22^{\circ} \mathrm{N}$
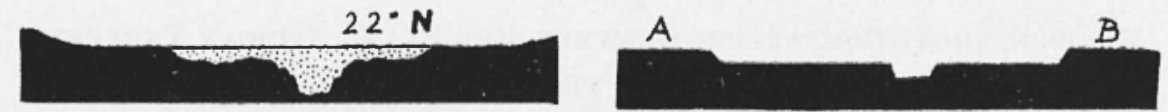

Fig. 4 - A comparison between the cross-section of Red Sea and Alpine Valley. (Red Sea after Girdler).

In addition to the morphological similarity between the shorelines of the Red Sea and the boundary-line of the Alpine Valley, the likeness appears by the existence of the rift of the Alpine Valley, too.

This rift is extending from the Northeastern end of the valley toward the Southwest (lunar directions in the IAU-meaning). However, it sems, that it doesn't reach the Southwestern end of the valley. Since this rift is situated by and large along the middle part of the valley - although its form is somewhat zigzagged, - it remind us very much 
to the fracture-zone of the Red Sea, mentioned above. Accordingly the cross-sections of the Red Sea and of the Alpine Valley must be very similar (Fig. 4).

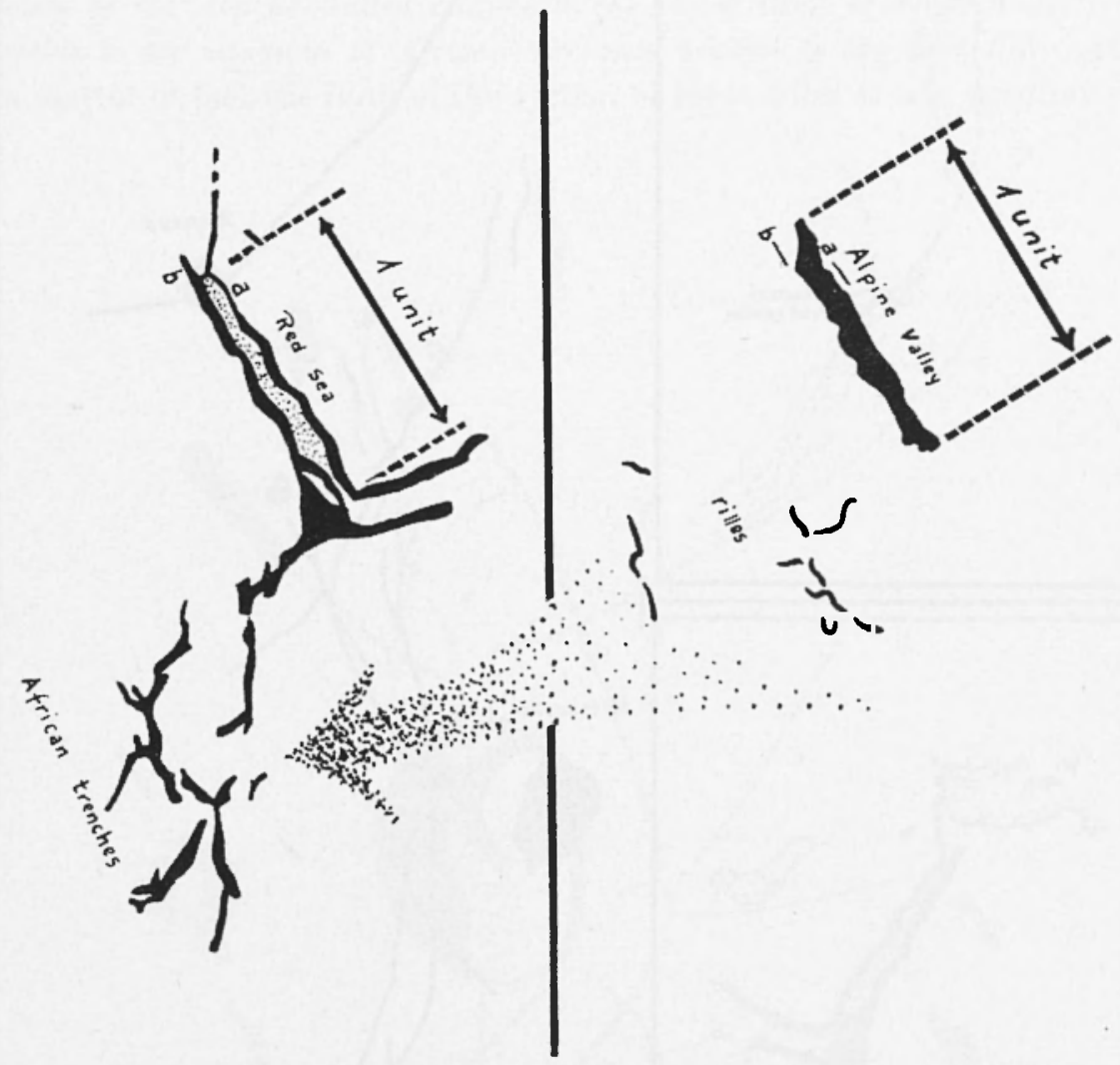

Fig. 5 - A comparison hetween the Red Sea - African Trenches region and the Alpine Valley area of the Moon, on the same scale. $a$ and $b$ : faults.

As it can be seen on Fig. 5, the Red Sea is bounded by mighthy faults which are in close connection with the so-called African Trenches. The connecting links between these trenches and the faults of the boundary of the Red Sea and of the Gulf of Aden respectively, are the Abyssinian Rift and the Afar Basin.

Let us regard the total length of the Red Sea and the medium length of the Alpine Valley as units of distances. In this case we may take a comparison between them on the same scale; namely the two units of distance were male to be equal on the drawing, that is 


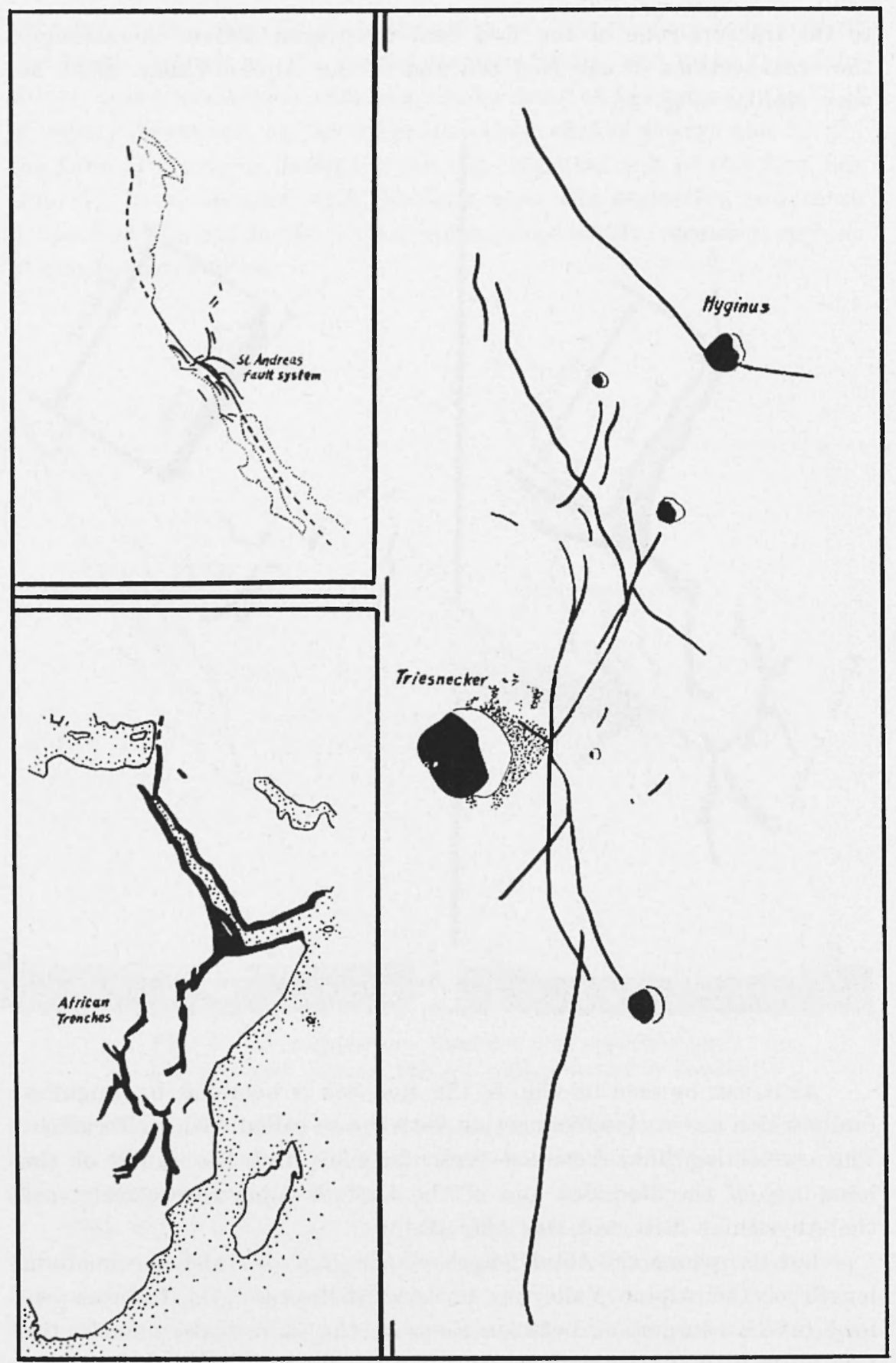

Fig. 6 - A comparison among the Triesnecker rille-system of the Moon, the African Trenches and Red Sea area of the Earth and the San Andreas system of faults of California, respectively, on different scales. 
the Alpine Valley was "enlarged" to the dimension of the Red Sea (Fig. 5).

According to this drawing the situation of the rilles in the proximity of the Alpine Valley relative to the valley itself is surprisingly similar to the situation of African. Trenches relative to the Red Sea. As a matter of fact the form of the system of these rilles of the proximity

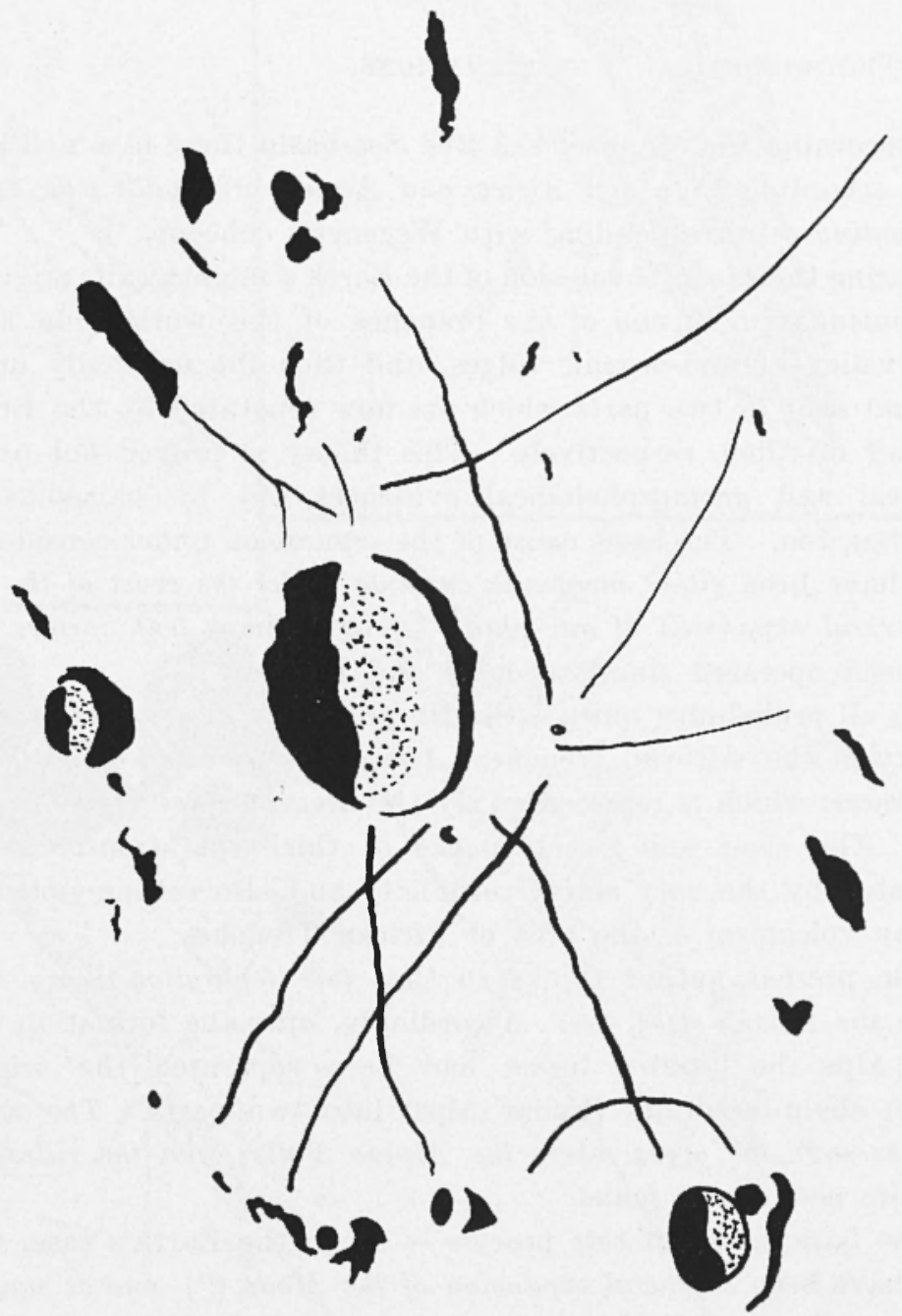

Fig. 7 - The cleft system of crater Ramsden of the Moon is very similar to the system of rilles of Triesnecker. Original drawing was made by L. F. BALL (after Moore). 
of Alpine Valley is also similar to the form of the system of African Trenches, although the trenches cover a greater area than the corresponding lunar rilles if we used the units of distance, mentioned earlier.

It is interesting to note that there are other systems of rilles on the Moon which are also similar in form to the African Trenches and San Andreas system of faults of the Earth ${ }^{16}$ ) (Figs. 6 and 7 ).

\section{Some Tectogenetical Considerations.}

Concerning the origin of the Red Sea-basin there is a well-known theory according to which Africa and Arabia originally was an uniform continent (corresponding with Wegener's concept).

During the general evolution of the Earth a mighthy rift originated, as a continuation of one of the branches of the world-wide system of rift-valley of mid-oceanic ridges, and thus the originally uniform mainland split in two parts which are now separated by the Red Sea and Gulf of Aden, respectively. This theory is proved not only by geological and geomorphological evidences but by palaeomagnetic researches, too. The basic cause of the separation under consideration might have been either magmatic currents under the crust of the Earth or a general expansion of our planet - or perhaps both factors might have been operated simultaneously and together.

By all probability quite a similar process is now in action on the territory of the African Trenches; Africa is separating along the zone of weakness, which is represented by the area of these trenches themselves. The clear and exact marks of this separation-process are manifested by the very active seismicity and also rather violent present-day volcanism of the area of African Trenches.

The present author thinks so that this separation-theory can be used in the Moon's case, too. Accordingly, after the formation of the Isunar Alps the internal forces had been separated the originally uniform chain-mountain (Lunar Alps) into two parts. The zones of weakness were the areas where the Alpine Valley and the rilles of its proximity now can be found.

The basic cause of this process - as in the Earth's case, too might have been a general expansion of the Moon (17) andlor magmatic currents under the solid lunar crust, the average thickness of which is estimated to be about only 20 kilometres, while in the case of the Earth the average crustal-thickness is about 33 kilometres. 


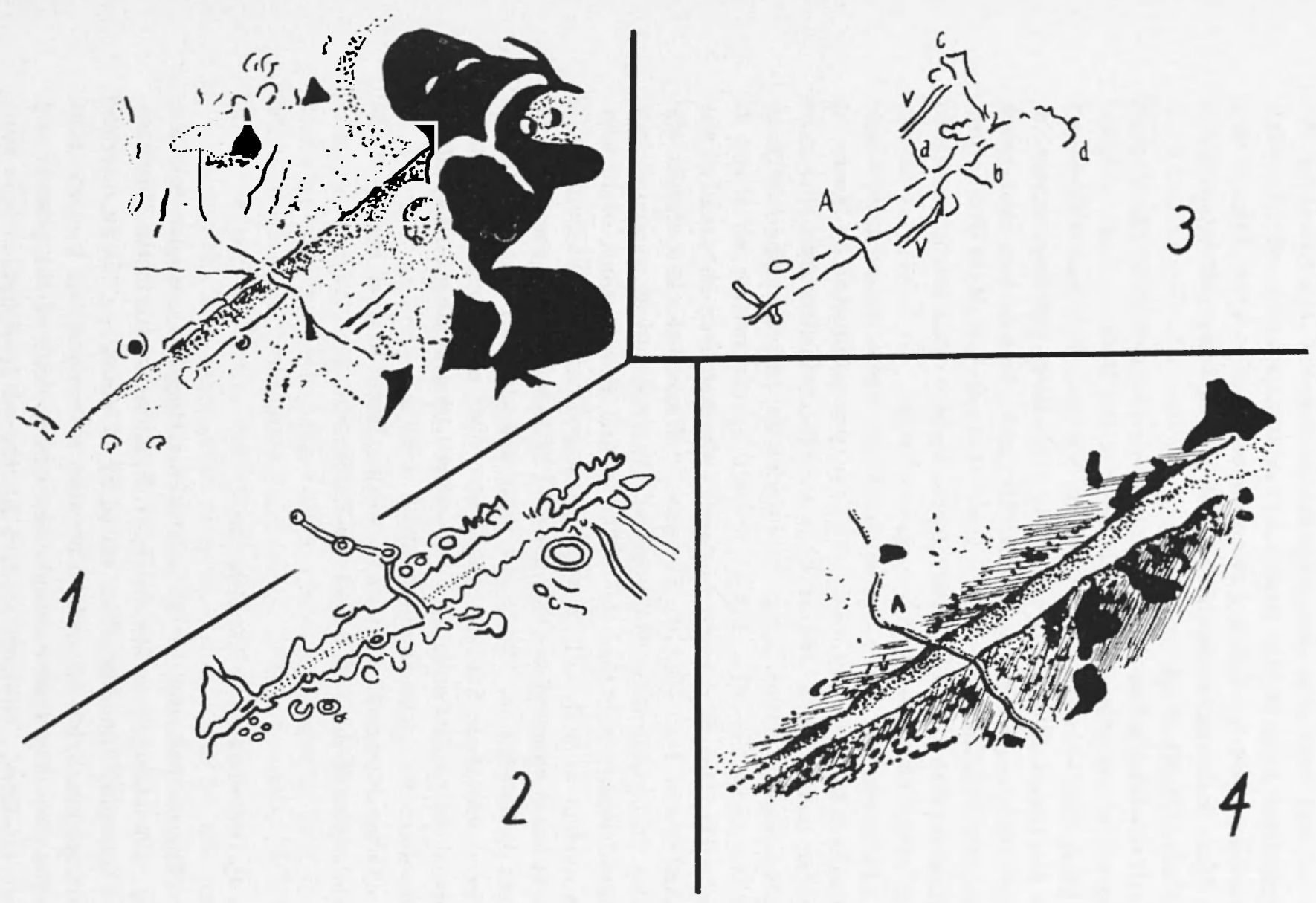

Fig. 8 - Drawings of the great Npine Valley of the Moon.

1: Elger's drawing (after the periodical "The Moon"); 2: Faulh's drawing (after Ley): 3: Woore's and Caltermole's drawings and its original text: "The Alpine Valley. It can be seen from the chart that there is a displacement of the nortern side of the valley to the east. ( $a$ and $c$ correspond to $b$ and $d$ on the opposite side of the structure). Jarallel valley occur at $v$. A sinuous cleft crosses the valley at $A$ ". 4: Ball's drawing (after Moore). 
At any rate it is clear that the existence of the rift along the longitudinal axis of the Alpine Valley is explainable only by such a process and in no case by the supposition of a great impact into the Mare Imbrium, since the form of the respective rift is zigzagged and not straight at all.

If this imagination, discussed above - is right then we can suppose that one of the seismically active areas of the MIoon - many millions of years ago - might have been the territory of Alpine Valley and the mentioned rilles in its proximity. Similarly the large system of lunar rilles, such are Ariadaeus, Hyginus, Triesnecker, and other rilles, for example the system along the edge of Mare Humorum, furthermore the Schröter- and Rheita Valleys, etc., might have also been places of rather violent seismic activity.

It seems that along the Alpine Valley there certain lateral movements might have occurred. This fact was established by Moore $\left(^{8}\right)$. He has mentioned a thinner fault (or rille) which crosses the great Alpine Valley. Other lunar explorers also had an opportunity to see the respective rille, but it doesn't appear neither on Photo I. nor in II. One of the first explorers, who had seen it visually, was Er.cien (18) in 1885 (Fig. 8). He says: "Where the cleft crosses the valley it is especially well marked and was noticed immediately I looked through the telescope. The $\mathrm{N}$ and $\mathrm{S}$ extensions of it were less evident at first, but later on I had good glimpses of both. The $\mathrm{N}$ extension winds among a number of little hills. One parallel range abuts on its SE side. The $\mathrm{S}$ extension was also only seen at intervals of good definition, but was traced as a cleft up to bringt mountain. Beyond (S) this its directions is prolonged by a number of low hills". And later: "... this is undoubtedly a rill".

It must mention that such crossing faults are not known at the middle part of the Red Sea of the Earth.

\section{On Planetology and Its Method.}

The method used in the present investigation is a planetologicar one. Planetology - as defined by G. N. KATTERFIELD in the Yearbook of Astronomy (Isondon, 1967, edited by P. Moore) - "is an intermediate science, lying somewhere between astronomy and geology, that studies the comparative morphology and geology of the planets and their satellites. Subjects studied by the planetologist include mor- 
phology, substance, structure and historical development of the litospheres of the planets and their satellites, while the basic methods of investigation employed are respectively morphogenetic, geological and in particular photogeological - with some adjustment made to allow for variations between physical condition on Earth and on other planets. In studying the nature and structure of the substances that make up the surface of the Moon and the other planets, wide use is made of astrophysical methods of investigation into such subjects as polarization, albedo, colorimetry and luminescence. In addition, use is made of radio astronomy and - for research into the volcanic structures of the Moon and Venus - spectroscopy. Statistical methods of research are also important for elucidating the origin and formation of planetary relief (i.e. the origin of lunar craters and cirques, the formation of lunar maria and the surface of Mars, and the origin of the oases on Mars) "The term "planetology" was given in the Webster's Approved Dictionary (Cleveland and New York, 1944) in this short form: "Planetology, a study and explanation of the surfaces of the planets".

In accordance with these definitions, given above, the method of planetological researches is based on the comparisons of the difierent features of the Earth and of the (terrestrial-type) planets and satellites. Planetology applies all the regularities and laws valid for the Earth, in the case of terrestrial-type celestial bodies.

The comparative planeto- and geophysics is also a new intermediate science. As planetology means the "geology" of the planets and satellites of terrestrial-type, - similarly, planetophysics deals with the physics of these celestial bodies, on the basis of comparison with the physical properties of the Earth. Thus, comparative planctoand geophysics deals - among others - with the internal composition, structure, tectono- and volcanophysics of terrestrial-type bodies; with their planetary magnetic field, radiatiln belt and magnetic tail; with their tectogenetical development and origin. The comparative planetoand geophysics is in close connection with general planetology.

During the last years great effort has been made by the part of many scientists all over the world for the organization of an international society of planetologists. It is hoped very much, that the INTERNATIONAL ASSOCIATION OF PLANETOLOGY (IAP) will be established in the year of 1968. The aim of IAP is to promote international co-operation in the field of planetology and comparative planeto- and geophysics, respectively. 


\section{REFERENCES}

(1) Watrs R. N. Jr., Photographs by Lunar Orbiter t. "Shy and Telescope" 34, 1 (1967).

(-) Batuwis R. B., The Measure of the Moon. Chicago, 1963.

( ${ }^{3}$ ) Baldwix R. B., The Face of the ILoon. Chicago, 1949.

(1) Beer W.-.ladefer J. II., Der Mond, Berlin, 1837.

$\left(^{5}\right)$ liemper G., Structure of the Moon's Surface. London, 1961.

$\left.{ }^{6}\right)$ Firsorf V. A., Strange Forld on the Moon. Isondon, 1959.

(') JwY W., Ranger to the Moon. New York, 1965.

(8) Catrennole P.-Moons P., The Cralers of the Moon. Ijondon, 1967.

$\left({ }^{9}\right)$ Toykins II. G., Nole of the Approximately Parallel Formalions on the Lunar Surface. "Journal of British Astronomical Association", 18, 125 (1907).

(10) HIDerviri P., Morphological Proofs of the Expansion of the Moon (in Hungarian). "Geofizikai Kozlemenyek", VI, 3-4 (1957).

(11) II JunvakI P.. The Physics of the Moon (in Hungarian). Budapest, 1962.

(12) Girdeder R. W., Iniliation of Continental Drift. "Nature", 194, 4828 (1962).

(13) GInLLER R. W., Geophysical Evidence on the Nature of Magmas and Intrusions Associaled with Rift Valleys. "Bulletin Volcanologique", XXVI (1963).

(14) Girdier R. W., Geophysical Studies of Rift Valleys. In "Physics and Chemistry of the Farth", 5, Jondon, 1963.

(15) Gindien R. W., The Formation of New Oceanic Crust. "Philosophical Transaction of the Royal Society", 258, (1965)

(16) II jugndiki P., Bemerkungen zur Selenologie. "Die Sterne ", 36, (1960).

(17) II EDERvarI P., The Morphology of the Moon's Surface and the Origin of its Fealures (in Hungarian). "Foldrajzi Kozlemenyek", VII, 2, (1959).

${ }^{18}$ ) Eugwr T. G., The Greal Alpine Talley. (A note and a drawing from Elger's original paper on the 23rd, January, 1885), published in "The Moon ", 8, 2, (1960). 